\title{
A Framework for Grouping of Equipment for Preventive Maintenance Planning
}

\author{
Iman Soleymani ${ }^{1}$, Kristoffer V. Sigsgaard ${ }^{1}$, Waqas Khalid ${ }^{1}$, Kasper B. Hansen ${ }^{1}$, Niels \\ Henrik Mortensen ${ }^{1}$ \\ ${ }^{1}$ Technical University of Denmark \\ imsole@mek.dtu.dk \\ krvsig@mek.dtu.dk \\ wakha@mek.dtu.dk \\ kabaha@mek.dtu.dk \\ nhmo@mek.dtu.dk
}

\begin{abstract}
One of the main challenges that maintenance organizations in asset-intensive companies are facing is the grouping of different equipment that can be maintained together. Companies can have hundreds of thousands pieces of equipment. Most of these pieces of equipment need different preventive maintenance plan to prevent them from breaking down. Having a systematic framework for the grouping of equipment helps develop a preventive maintenance plan for each group instead of each piece of equipment. This will reduce the number of preventive maintenance plans in the company and thereby reduce the complexity of managing the preventive maintenance plans. There are well-developed studies about grouping execution of maintenance activities during the scheduling phase, after the activities are planned. However, the challenge of grouping equipment to be maintained according to the same preventive maintenance plans suffers from lack of academic and empirical studies. Product management practices in the companies are also suffering from the same issue. By increasing the need for customised products, companies tend to create huge variety in their product assortments. Managing hundreds of products without the ability to group them systematically is a very complex challenge. Product family and product architecture theory is a well-developed theory that helps companies manage such complexity. According to this theory, companies, by analysing and understating their products from different viewpoints, will be able to define families of products based on the identified criteria and similarities. This study, by getting inspired from the product family and product architecture theory, investigates how this theory can be used to manage the complexity in managing the preventive maintenance plans. Therefore, this study is focused on: (1) Investigating how product family and product architecture theory can be utilized in developing a framework for grouping of equipment; (2) Systematically identifying and classifying the possible criteria to be considered when grouping equipment that can be maintained together; (3) Reporting the potential benefits by analysing the framework in the context of a case company.

Keywords: Maintenance Activities, Maintenance Plan, Product Families, Product Architecture, Complexity
\end{abstract}




\section{Introduction}

The tough requirements on companies to utilize their production capacity due to high competition in gaining market shares, reveals the importance of keeping a company running efficiently. To do so, companies need to ensure that all of their equipment is functioning optimally and do not have frequent unplanned breakdowns. A breakdown in critical equipment can have considerable consequences in terms of safety, productivity, and profitability (Alsyouf, 2007). These undesirable breakdowns can be avoided by conducting routine preventive maintenance to improve equipment reliability (Wang, 2002). In order to develop a routine preventive maintenance plan, all the maintenance actions and their frequency, required resources, and priorities should be defined and designed in an equipment-specific document called the maintenance plan (Kelly, 2006). In other words, a maintenance plan is a document that defines maintenance actions that are required to be done to proactively maintain equipment in a facility (LCE, 2011). In an asset-intensive organization with thousands pieces of equipment, there can be a significant number of maintenance plans. Each maintenance plan is developed to maintain a piece of equipment. If these maintenance plans can be combined effectively, the complexity of the maintenance management in the company will be reduced. Design and development of the right maintenance plan for a group of equipment is a complex task due to the diversity of the equipment, their associated breakdowns, and different criteria that need to be considered (Shafiee, Labib, Maiti, \& Starr, 2019). One of the main questions that arise is what criteria should be considered when grouping the equipment. If the optimal group can be designed and developed, the number of maintenance work orders which are released by maintenance plans can be reduced and therefore, resources to plan and execute the maintenance activities can be utilized in more optimal way (Hameed \& Vatn, 2012).

Product management practices in the companies are also suffering from a similar issue. By increasing the need for customised products, companies tend to create a huge variety in their product assortments (Harlou, 2006). Managing hundreds of products without being able to define product families becomes a very complex challenge (Halman, Hofer, \& van Vuuren, 2006). A product family is defined as a group of related products that share the same characteristics (Simpson, Siddique, \& Jiao, 2006). The challenge here is to develop methods that group the products into product families and find the right number of product families. Finding the right balance between the two ultimate cases, having one group that contains all products or having one product per product group, contributes in the success of the whole practice (Askhøj \& Mortensen, 2019). Product architecture and product family theory is a proven way to design and develop product groups and finding the right place in the spectrum by understanding the architecture of the products (Askhøj \& Mortensen, 2019; Thevenot \& Simpson, 2006). As it is suggested by Harlou (2006) and Mortensen et al. (2011), there are three main aspects of interest when modelling the variety of a product family. These aspects are the market view, the product view, and the production view. The overall view of these three aspects is called product family master plan (PFMP) (Harlou, 2006; Mortensen et al., 2011). The market view looks at the product from the customer's viewpoint to answer the question: what are the features and application characteristics that are important for the customer? The product view highlights the building principles of a product family. The production view gives insight into the building principles of production and how these principles support the launch of future products (Harlou, 2006; Mortensen et al., 2011).

This study seeks to investigate how product family and product architecture theory can be utilized when developing a framework for grouping of equipment that can be maintained together. It is expected that implementing this framework will reduce the number of 
maintenance plans in a company, which in turn will lead to less complex maintenance management processes. Inspired by the product family theory, a maintenance plan can be seen as a product that is developed to fulfil the maintenance requirements of a piece of equipment. Therefore, the equipment can be seen as a customer and the process of developing the maintenance plan is similar to the production view in the product family theory (Figure 1).
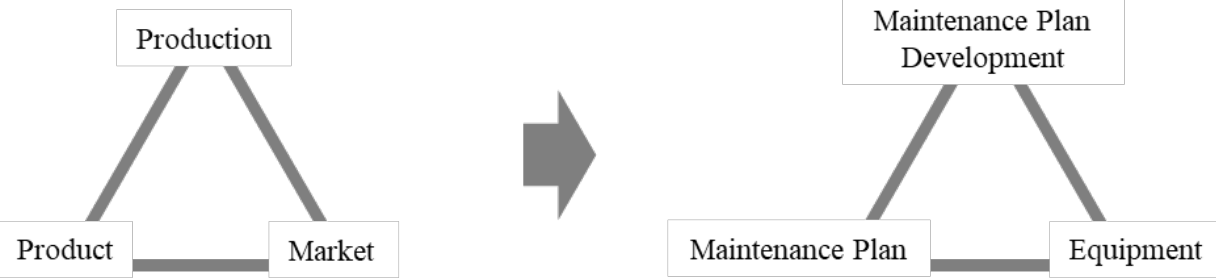

Figure 1: Three main aspects of developing maintenance plan groups, inspired by PFMP

It should be added, literature holds different methods for the grouping of maintenance activities during the scheduling phase after the maintenance work orders have been issued. However, this study focuses on developing a framework to group the equipment and their maintenance activities in the planning phase, which is before the maintenance work orders are issued (for better understanding of the difference between planning and scheduling steps in the management of a maintenance work order, refer to section 3.1).

Therefore, this study is focused on:

(1) Investigating how product family and product architecture theory can be utilized in developing a framework for grouping of equipment;

(2) Systematically identifying and classifying the possible criteria to be considered when grouping equipment that can be maintained together;

(3) Reporting the potential benefits by analysing the framework in the context of a case company.

\section{Research methodology}

A case study is used in this study as the main research strategy. According to Saunders et al. (2009), case study research design best fits with studies where the researchers need to go into detail in a narrow case to be able to understand a phenomenon and develop predictions about the defined situation. In this study, qualitative data is used to discover and understand the different criteria that can affect the equipment grouping when developing maintenance plans. In addition, quantitative data is used to analyse the potential effects of the developed framework. Therefore, it can be said that the data gathering choice of this study according to what Saunders et al. (2009) suggested is the mixed-method approach, which refers to cases where both quantitative and qualitative techniques are used. The time horizon of this paper is cross-sectional. This is because all the steps that are passed during the research are limited to the seven-month period in which the study was conducted.

The researchers will use qualitative data from a literature review in the field of maintenance and asset management as well as product family and product architecture, interviews with the subject matter experts and written procedures and guidelines from the case company. These resources are used to understand the current processes for developing maintenance plans, as well as to develop a new framework for equipment grouping. Then, quantitative data from historical maintenance records in the case company will be extracted and used to compare and evaluate the as-is situation and the to-be situation as suggested by the framework. 


\section{The case company}

The case company is a multi-national Oil \& Gas Company and one of the six supermajor oil companies in the world. The case company covers the entire chain of oil \& gas including upstream and downstream operations. The activities of the case company in the Danish part of the North Sea, which includes operating 23 fields, is the scope of this study.

The equipment, maintenance plans, and maintenance strategies and documents from the case company, as well as maintenance personnel's opinions and experiences are used in this study to understand the current practices and challenges the company is facing in managing its preventive maintenance. Using the insight from the case company along with the product family and product architecture theory, a framework for systematically grouping of equipment and developing maintenance plans is designed. The study is concluded by evaluating the developed framework through analysis of the potential benefits from its implementation on one of the company's offshore platforms.

\subsection{Current maintenance work management at the case company}

The case company has developed its own way of managing the maintenance process, which according to the company, is based on industry best practice and proven within asset-intensive industries. The maintenance management process in the case company is based on the Deming circle concept of continual improvement (plan, do, check, act) (Swamidass, 2000) where over a period of time, history of failures, equipment reliability and maintenance activities are reviewed and used to enhance the existing maintenance strategies. To manage and control this process, the case company uses a computerised maintenance management system (CMMS). CMMS is software that centralizes maintenance information and facilitates the processes of maintenance operations (IBM Watson IoT, n.d.). The CMMS that the company is using is SAP PM, which is the plant maintenance module of SAP; SAP is the enterprise resource planning (ERP) system that the company uses.

The six main steps of the company maintenance management process are: Identify, Prioritise, Plan, Schedule, Execute, and Close out (Figure 2) and is applicable to both preventive and corrective maintenance activities.

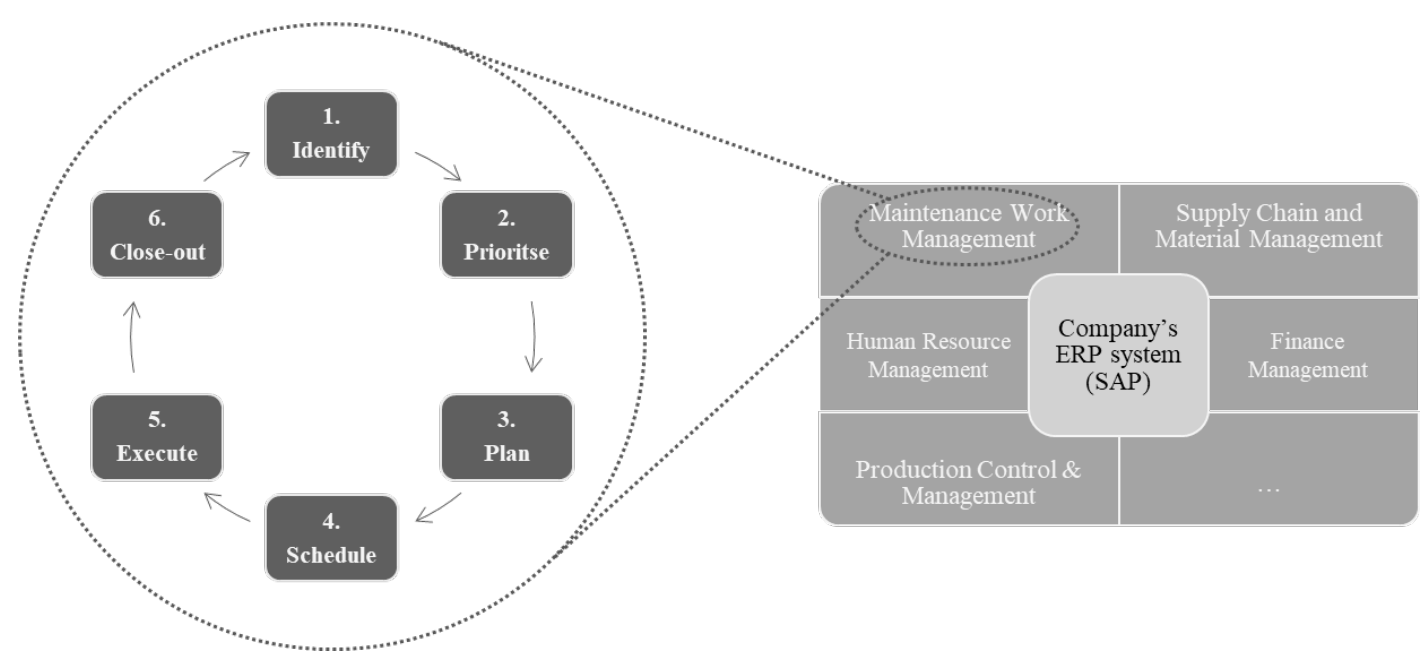

Figure 2: Maintenance management process at the case company

The identify, prioritise, and plan steps are divided in to two streams of activities; preventive maintenance actions and corrective maintenance actions. The preventive part is focused on defining, prioritising, and planning the maintenance activities that the company needs to keep its equipment running with planned preventive maintenance. The corrective part is focused on 
identifying, recording, prioritising, and planning the required maintenance actions to fix broken equipment. The scheduling and execution steps define the standard working procedures for assigning right timeslot and the physical execution of the identified maintenance actions. The close out step is focused on ensuring that all the reports are recorded correctly, so the information can be used for further analysis and improvement purposes. This study is focused on the first three steps related to preventive maintenance activities, i.e. identify, prioritise, and plan.

\subsection{Current maintenance plan design and development and the related challenges}

The current procedure for developing and commissioning the maintenance plans in the case company is divided into two main parts; 1) Develop and Design the maintenance plan, 2) Add the maintenance plan into the CMMS.

The first part, which is about developing and designing maintenance plans, has three steps. According to the defined process in the case company, only equipment with a high-risk level need to have planned preventive maintenance and the equipment with a medium-risk level or a low-risk level will only have corrective maintenance. Therefore, the first step is focused on identifying the equipment with high-risk level by estimating the risk. The next step is to conduct a failure mode and effect analysis (FMEA). This analysis produces a list of required maintenance actions for each piece of equipment. FMEA is an analytical method from reliability engineering developed to help identify the main functions and potential failures or failure modes for equipment in advance and develop maintenance actions to prevent these failures from happening (Göbel, 2016; Salah, Osman, \& Hosny, 2018). Equipment manufacturer recommendations, experts' experiences, standards, historical data, and industry best practices are some of the sources of knowledge that can support the FMEA process. In the last step, based on the developed list of maintenance actions, the maintenance plan for each equipment is designed. A maintenance plan should include the list of maintenance actions (e.g. lubrication, inspection, replacement, etc.) and their priority, responsible, frequency, operations execution steps, resources, equipment's working condition during maintenance operation, and estimated required time for the execution of maintenance activities (Figure 3).

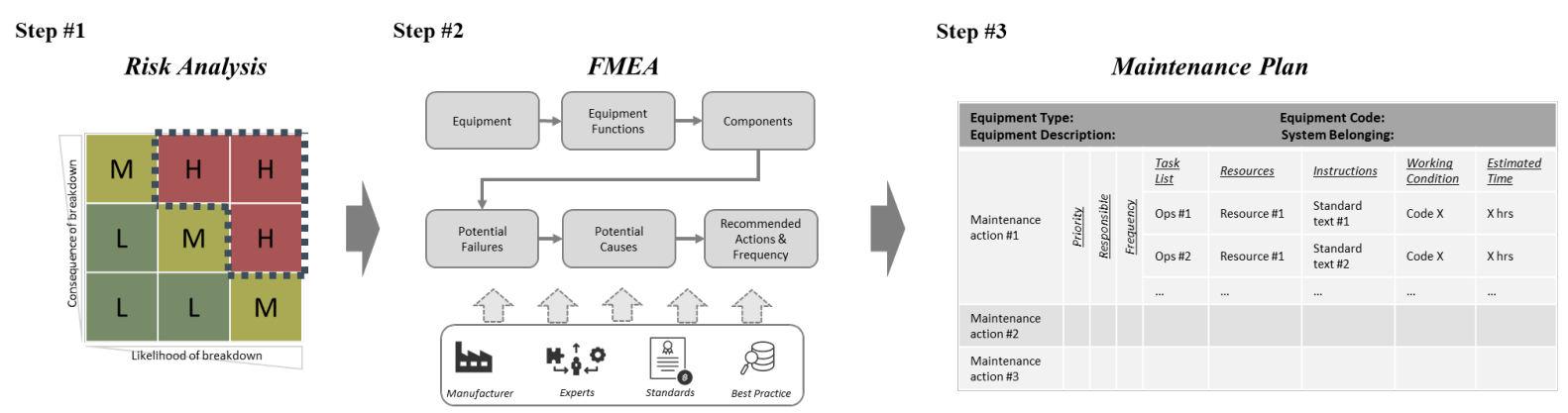

Figure 3: Current framework for developing and designing maintenance plans

The second part is about adding the developed and designed maintenance plan into the company's CMMS. This part of the process starts by checking the CMMS for existing, similar maintenance plans in terms of frequency and scope of activities. In the current process, there is not a well-developed structure in the company for checking the similarity between the existing maintenance plan and the new one. This process is based on the experience and abilities of the operator. If the operator finds a similar maintenance plan, the new maintenance plan will be grouped with the existing one. If a similar maintenance plan does not exist or the operator cannot locate the similar maintenance plan, a new maintenance plan will be added to the system. 
After getting the approval, the maintenance plan will be activated and control the release of maintenance work orders (Figure 4).

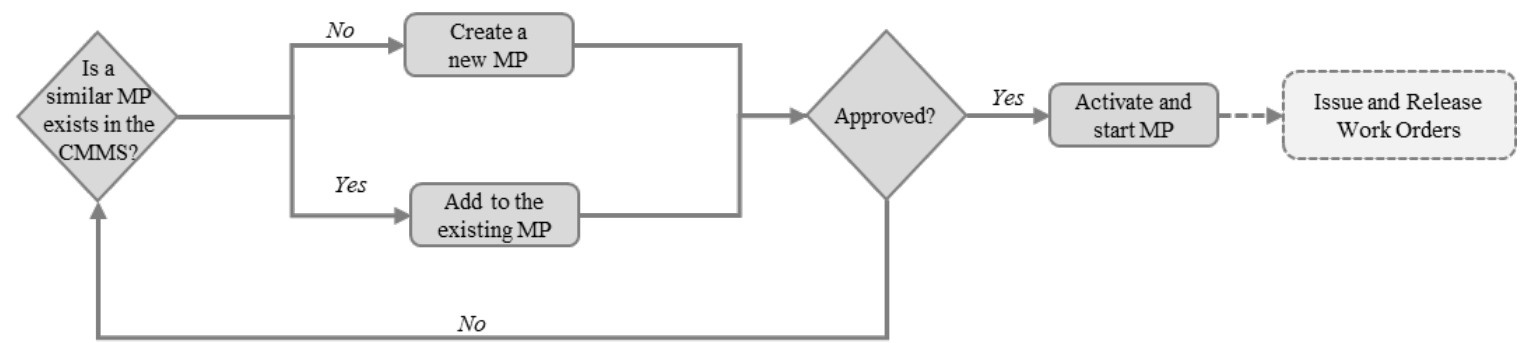

Figure 4: Adding the developed and designed maintenance plan (MP) into the CMMS

By looking at the described process, it is clear that there is not a structure for systematically grouping the maintenance plans. It can be concluded, that despite the discussed benefits of grouping the equipment into the same maintenance plan, this is not a part of maintenance plan development procedure in the case company. This has led to a higher number of maintenance plans that add to the complexity of managing and updating the maintenance activities in the case company. Moreover, as long as the creation and release of maintenance work orders is controlled by the maintenance plans, having a high number of maintenance plans means having high number of maintenance work orders.

\section{Proposed maintenance plan design framework}

The overall benefits of grouping equipment to be maintained by the same maintenance plan is discussed in the previous section. In this section, the developed framework for the grouping is presented and its potential benefits are discussed in more details.

The first step in grouping the equipment is developing a basis for grouping logic. In product family theory, the product and market views must be understood in order to develop the product families. Product families are equivalent to groups of maintenance plans in this study. Market view, as it is explained in the introduction section (Section 1), is equivalent to the equipment view in this study and the list of required maintenance actions, i.e. the maintenance plan, is considered as the product. Therefore, a step toward designing the maintenance plan groups is to understand the equipment that will be maintained according to each maintenance plan and the maintenance plan itself. A list of potential criteria that can affect development of maintenance plan groups is identified by studying the maintenance management documents and having semi-instructed interviews within the case company. The interviews were focused on understanding the criteria that should be utilised in understanding the equipment and its maintenance requirements based on the subject matter experts experiences. By summing up the gained knowledge from the documents and interviews, a list of the possible criteria that can be used in developing the framework for grouping of maintenance plans was developed (Table 1). 
Table 1: Identified criteria as a basis for grouping of equipment

\begin{tabular}{|l|l|c|}
\hline \multicolumn{1}{|c|}{ Criterion } & \multicolumn{1}{c|}{ What does it show } & Example \\
\hline Platform & In what platform the equipment is installed & Platform \#1 \\
\hline Functional Location & What is the exact location of the equipment & N/A \\
\hline System & What system the equipment belongs to & Pump sentrifugal \\
\hline Class & Primary function of the equipment & High \\
\hline Type & What is the type of the equipment & Total shutdown \\
\hline Criticality & Criticality level of the equipment in terms of its associated risks & 25 hours \\
\hline Shutdown Effect & Working condition of the equipment during maintenance & Medium \\
\hline Job Size & Estimated work load for execution of the maintenance activity & Pum \\
\hline Priority & Priority of the maintenance activity & Electrical Engineer \& Filter \\
\hline Resources & What resources is required to execution of the maintenance & Inspection \\
\hline Type of the Job & What is the type of maintenance activity & Every 6 months \\
\hline Frequency & How frequently the activity should be executed &
\end{tabular}

The goal is to keep the criteria on a generic level. However, the example criteria listed in Table 1 are relevant to the case company context and their value can be extracted from the case company's CMMS. It should be mentioned that the main contribution of this study is the framework for grouping of equipment and the criteria might be changed according to the purpose of different studies. Other possible criteria could be age, technology level, historical failure records, reliability level, redundancy rate, etc. Criteria should be identified and validated for each study through a proper data gathering process like performed for this study: e.g. interviews with subject matter experts, company's document and guidelines, etc.

To limit the complexity of maintenance activities, maintenance plans can then be developed for a group of equipment based on the identified criteria. Considering the identified criteria (Table 1), it can be seen that these criteria can be categorised in to two categories (Figure 5). One category contains the criteria that are relevant to the equipment and its primary function that can be used for grouping of equipment and defining the virtual boundary for each group. Virtual boundary is defined as the interface between an item and its surroundings and helps avoid overlap of different equipment (ISO 14224, 2016). The other category contains the criteria that are relevant to the maintenance actions that are required to maintain the equipment. This category can be used for grouping of maintenance actions. In the maintenance action category, type of the maintenance action determines the value for other criteria; therefore, these criteria are shown under the action type in Figure 5.
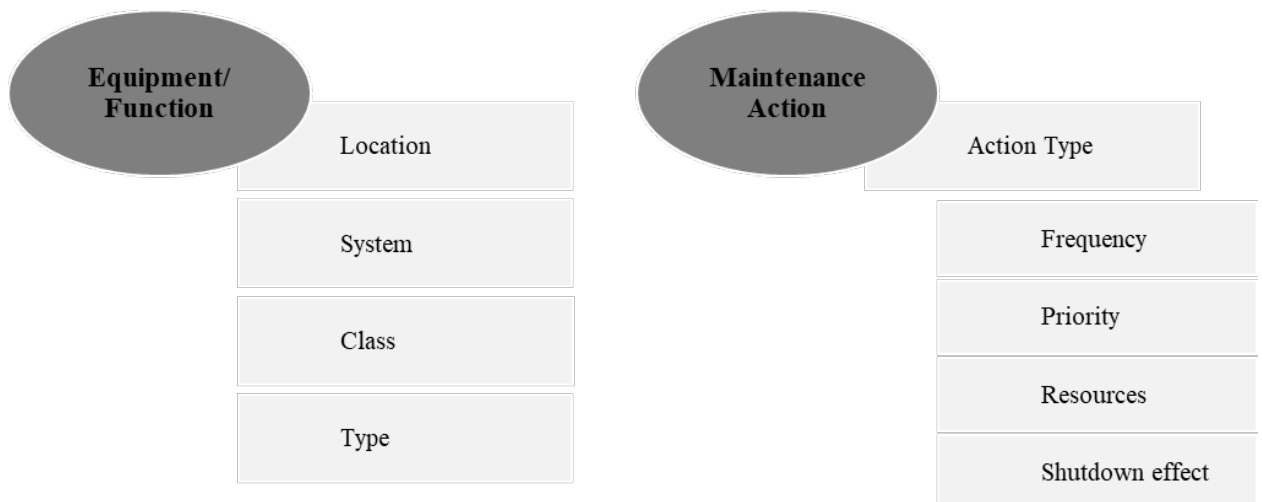

Figure 5: Classifying the identified criteria

The first category of criteria, Equipment/Function in Figure 5, is used for designing the boundaries for each group of equipment. Equipment in each boundary can be further grouped 
into subgroups. The basis for defining subgroups is by considering the second category of identified criteria, Maintenance Action in Figure 5, which will be defined by conducting FMEA. Each subgroup will include equipment with same maintenance actions requirement. Figure 6 shows a schematic representation of the described recommended framework for developing maintenance plans. The changed or added steps from the current framework (Figure 3) are highlighted. As an example, in Figure 6 the boundary is assumed to be: Ball Valves in the Valve class in the Process System on Platform \#1.

Step \#1

Risk Analysis

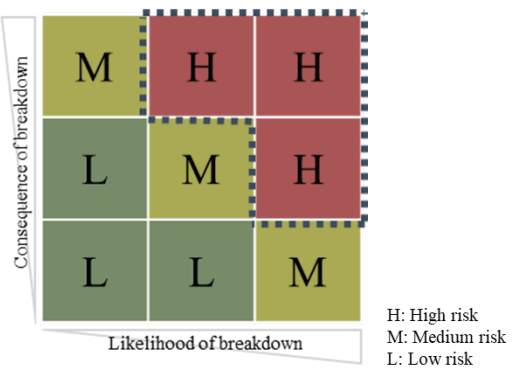

Step \#3

FMEA for each equipment in the boundary

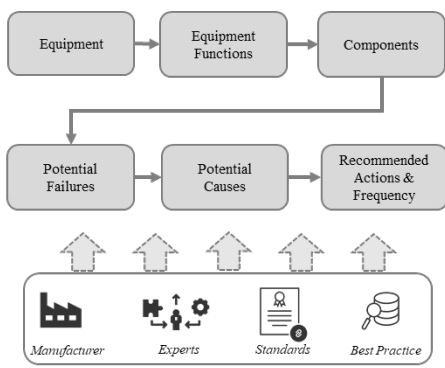

Step \#2

Define Equipment Boundary for high risk equipment
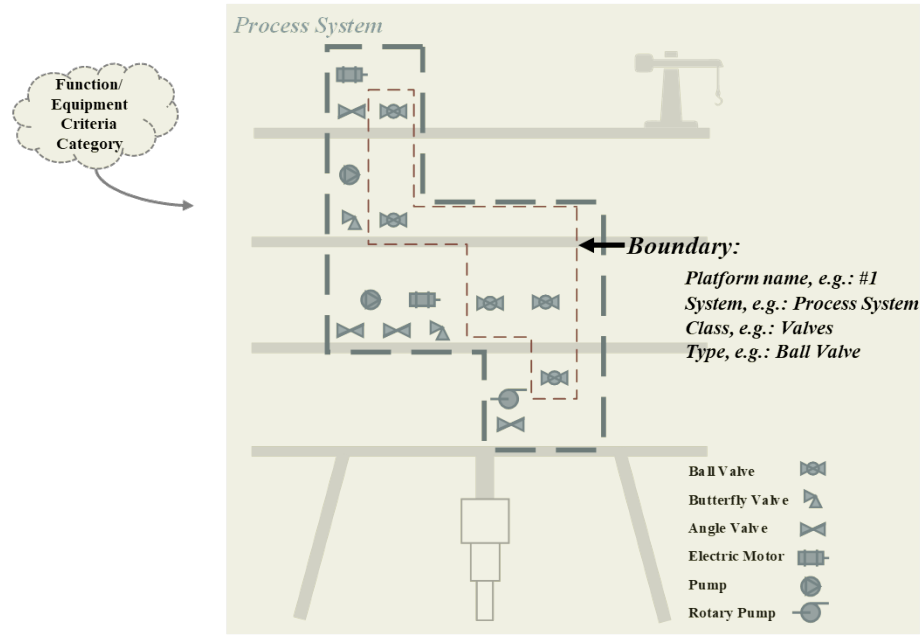

Step \#4

Define the subgroups and develop Maintenance Plan

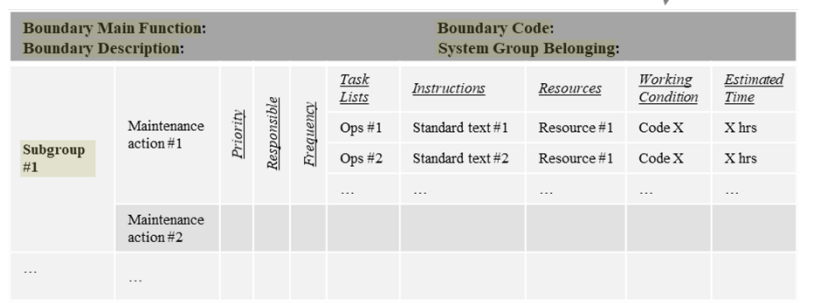

Figure 6: Proposed framework for developing and designing maintenance plans

The first step in Figure 6 is the same as the current process in the case company: to identify the high-risk equipment on the platform. In the second step, the equipment/function class of criteria (refer to Figure 5) is used to define the boundaries, i.e. location, system, class, and type of equipment. The third step is performing the FMEA to develop the required maintenance actions for each equipment within the developed boundaries. In the last step, the output of step three is used in designing the maintenance plan for each of the developed boundaries. In this step, by analysing maintenance action category of criteria (refer to Figure 5) within each of the boundaries, the developed maintenance plans are divided into subgroups.

As explained in the section 3.2, the current procedure for developing and commissioning the maintenance plans in the case company is divided in to two main parts: 1) Develop and design the maintenance plan, 2) Add the maintenance plan to the CMMS. By using the defined method, the equipment are grouped based on the defined boundaries. Therefore, there is no need to check for similar existing maintenance plans when adding the new maintenance plan into the CMMS. 
This change the Add the maintenance plan in to the CMMS part of the process as illustrated in Figure 7.

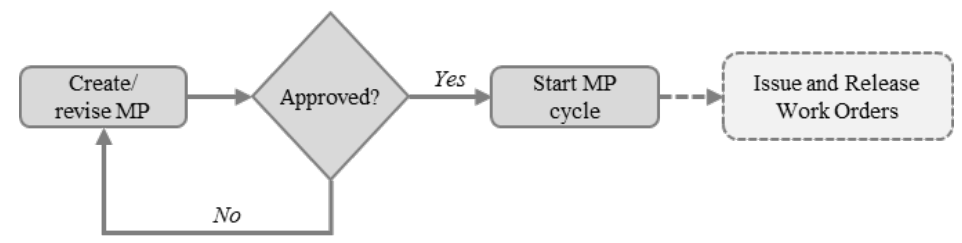

Figure 7: To-be adding the developed and designed maintenance plan (MP) in to the CMMS

In the next section of this study (Section 5), the proposed framework is analysed in context of one of the platforms in the case company and its potential results are presented. The analysis of the framework is limited to the first two steps of the proposed framework. To implement the third and fourth steps, a thorough FMEA study for each boundary is required. Conducting FMEA is out of scope of this study as it requires reliability engineers form different disciplines (Carlson, 2012). However, this is suggested as a possible area for future studies.

\section{Potential results of the proposed framework}

The studied platform is a processing platform with 12,953 pieces of equipment divided into five different systems. Out of the 12,953 pieces of equipment, 4,356 are evaluated as high-risk equipment based on their consequence of failure and likelihood of failure. In the current CMMS setup in the case company, these 4,356 pieces of equipment are maintained through 193 active maintenance plans.

According to the proposed framework, in order to develop the new maintenance plans, boundaries should first be developed. For the 4,356 pieces of high-risk equipment on the platform, the existing information for systems, classes, and types of equipment from the company's CMMS are utilised to define the boundaries. Based on this information, the 4,356 pieces of high-risk equipment are grouped according to possible combinations of 5 systems, 31 classes, and 78 types of equipment. This yielded to 147 developed virtual boundaries. Figure 8 shows an illustration of the development of these possible boundaries based on the mentioned criteria. The values for each criteria is replaced by a number due to confidentiality.
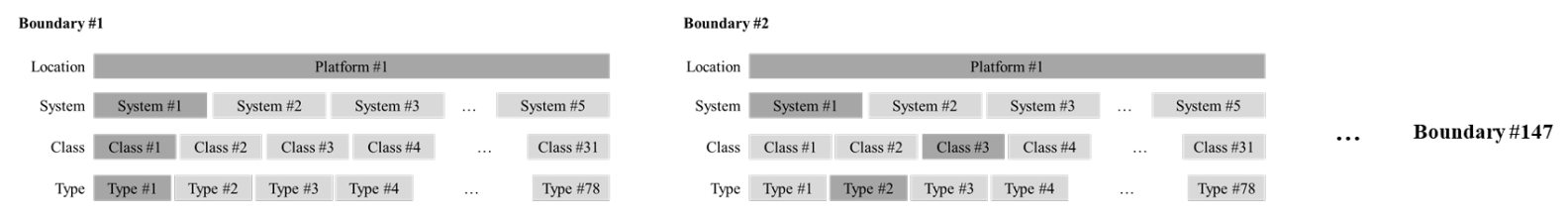

Figure 8: An illustration of developing virtual boundaries in the case study

These 147 different boundaries show the 147 unique groups of equipment that the maintenance plan should be developed for each group based on conducting a FMEA study. This number is the initial potential number for the number of to-be maintenance plans (Figure 9). 


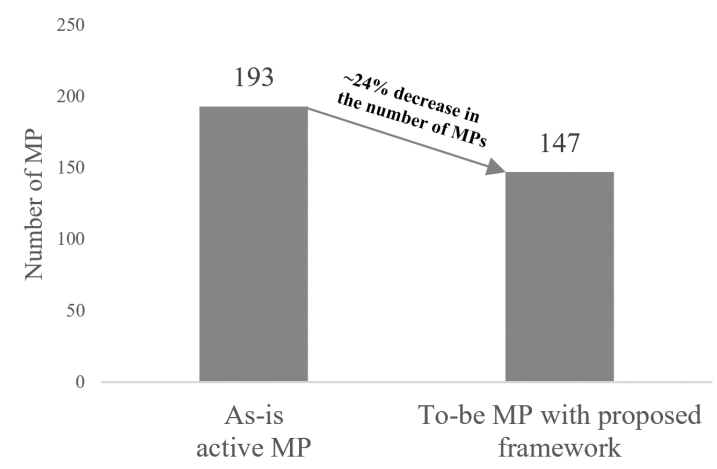

Figure 9: Comparison between the as-is and to-be number of maintenance plans (MP)

Figure 9 shows, by using the proposed method, there is a potential decrease in the number of maintenance plans by almost $24 \%$. This decrease in the number of maintenance plan groups means lowered complexity in the management and execution of the maintenance activities and fewer work orders. The decrease in the number of work orders will also enable an easier scheduling process. Consequently, the scheduling of the maintenance work orders can be more precise and the company will be more compliant with the planned activities. However, another criterion should be considered. By using these 147 groups, some of the groups will contain a large amount of equipment, which might make it impossible to execute the maintenance work orders. Future studies should investigate how to consider the forecasted job size and available resources when grouping the maintenance plans.

\section{Discussion and conclusion}

The purpose of this study is to develop a framework for grouping of equipment that can be maintained with the same maintenance plan. In asset-intensive companies with hundreds of thousands pieces of equipment, the number of maintenance plans can be very high. Having too many maintenance plans will lead to having an unmanageable level of complexity. Therefore, being able to group the equipment and develop new maintenance plans that can be used in maintaining more than one piece of equipment will reduce the mentioned complexity.

In the product world, the same issue exists. By increasing the need for customised products, companies tend to create huge variety in their product assortments. Product architecture and product family theory is a proven way to reduce this variety by grouping products into product families. The product architecture and product family theory is therefore utilized to develop a framework for grouping the equipment by acquiring an understanding of the three views: equipment, maintenance plans, and development of maintenance plans. Each piece of equipment is seen as a customer and each maintenance plan is a customised product. The preliminary study at a multi-national oil \& gas company showed a potential decrease in the number of maintenance plans of up to $24 \%$, which will lead to less complex and more accurate management and execution of maintenance activities in the case company.

The grouping of equipment by shared maintenance activities based on the product family theory is a new field of study. This initial study shows considerable potential for future studies and improvement opportunities. An interesting area for future work is taking the next step and conducting the FMEA study to develop the subgroups within each maintenance plan and analyse the complete effect of proposed framework. Another possibility for future studies is finding the right number for groups of maintenance plans. One side of the spectrum is having one maintenance plan per piece of equipment. This means a completely tailored maintenance plan designed specifically for that piece of equipment's unique needs, which can increase the equipment reliability level. However, in a company with hundreds of thousands pieces of 
equipment, having one maintenance plan for each piece of equipment means an unmanageable level of complexity and high costs for managing and controlling of the maintenance plans. The other end of the spectrum is having one maintenance plan for maintaining all equipment. In theory, having one maintenance plan should lead into low complexity in terms of managing the maintenance plan. However, it is not realistically feasible to maintain all equipment with same maintenance plan as different equipment has different maintenance requirements. Therefore, finding the right balance between these two extremes is an important challenge to address.

\section{Acknowledgement}

The paper acknowledges the support and funds provided by the Danish Hydrocarbon Research \& Technology Centre (DHRTC) for this study.

\section{References}

Alsyouf, I. (2007). The role of maintenance in improving companies' productivity and profitability. International Journal of Production Economics, 105(1), 70-78. https://doi.org/10.1016/j.ijpe.2004.06.057

Askhøj, C., \& Mortensen, N. H. (2019). Deciding on the total number of product architectures. Concurrent Engineering Research and Applications. https://doi.org/10.1177/1063293X19888968

Carlson, C. S. (2012). Effective FMEAs. https://doi.org/10.1002/9781118312575

Göbel, A. (2016). FMEA. In W. Merkle (Ed.), Risk Management in Medicine (pp. 93-96). https://doi.org/10.1007/978-3-662-47407-5_11

Halman, J. I. M., Hofer, A. P., \& van Vuuren, W. (2006). Platform-Driven Development of Product Families. In T. W. Simpson, Z. Siddique, \& J. R. Jiao (Eds.), Product Platform and Product Family Design: Methods and Applications (pp. 27-47). https://doi.org/10.1007/0-387-29197-0_3

Hameed, Z., \& Vatn, J. (2012). Role of grouping in the development of an overall maintenance optimization framework for offshore wind turbines. Proceedings of the Institution of Mechanical Engineers, Part O: Journal of Risk and Reliability, 226(6), 584-601. https://doi.org/10.1177/1748006X12464616

Harlou, U. (2006). Developing product families based on architectures: Contribution to a theory of product families (Technical University of Denmark). https://doi.org/10.1007/978-3-319-60588-3_7

IBM Watson IoT. (n.d.). What is a CMMS? Retrieved February 12, 2020, from https://www.ibm.com/internet-of-things/solutions/enterprise-asset-management/what-isa-cmms

ISO 14224. (2016). Petroleum, petrochemical and natural gas industries - Collection and exchange of reliability and maintenance data for equipment (ISO 14224:2016). International Organization for Standardization.

Kelly, A. (2006). Preventive maintenance decision-making - Part 2: Maintenance task selection. In Plant Maintenance Management Set. https://doi.org/10.1016/b978-0750669955/50038-2

LCE. (2011). Developing Equipment Maintenance Plans. Retrieved February 26, 2020, from https://www.lce.com/Developing-Equipment-Maintenance-Plans-1113.html 
Mortensen, N. H., Hansen, C. L., Hvam, L., \& Andreasen, M. M. (2011). Proactive modeling of market, product and production architectures. ICED 11 - 18th International Conference on Engineering Design - Impacting Society Through Engineering Design, 4(August), 133144.

Salah, M., Osman, H., \& Hosny, O. (2018). Performance-Based Reliability-Centered Maintenance Planning for Hospital Facilities. Journal of Performance of Constructed Facilities, 32(1), 1-7. https://doi.org/10.1061/(ASCE)CF.1943-5509.0001112

Saunders, M., Lewis, P., \& Thornhill, A. (2009). Research Methods for business students (Fifth). Prentice Hall.

Shafiee, M., Labib, A., Maiti, J., \& Starr, A. (2019). Maintenance strategy selection for multicomponent systems using a combined analytic network process and cost-risk criticality model. Proceedings of the Institution of Mechanical Engineers, Part O: Journal of Risk and Reliability, 233(2), 89-104. https://doi.org/10.1177/1748006X17712071

Simpson, T. W., Siddique, Z., \& Jiao, J. R. (2006). Platform-Based Product Family Development. In T. W. Simpson, Z. Siddique, \& J. R. Jiao (Eds.), Product Platform and Product Family Design: Methods and Applications (pp. 1-15). https://doi.org/10.1007/0387-29197-0_1

Swamidass, P. M. (Ed.). (2000). Deming cycle, plan-do-check-act (PDCA). In Encyclopedia of Production and Manufacturing Management (p. 155). https://doi.org/10.1007/1-40200612-8_229

Thevenot, H. J., \& Simpson, T. W. (2006). Commonality Indices for Assessing Product Families. In T. W. Simpson, Z. Siddique, \& J. R. Jiao (Eds.), Product Platform and Product Family Design: Methods and Applications (pp. 107-129). https://doi.org/10.1007/0-387-29197-0_7

Wang, H. (2002). A survey of maintenance policies of deteriorating systems. European Journal of Operational Research, 139(3), 469-489. 